\title{
Relationship between self-transcendence and physically-healthy patients under hemodialysis in participating in peer-support group; a randomized clinical trial
}

\author{
Akram Malek Khahi ${ }^{1}$, Maryam Mohseny ${ }^{2}$, Fatemeh Soleimany ${ }^{1}$, Marjan Vejdani ${ }^{3}$, Avina Keshvardoost ${ }^{4}$, \\ Parastoo Amiri ${ }^{*}$ \\ ${ }^{1}$ Heshmatieh Hospital, Sabzerar University of Medical Sciences, Sabzevar, Iran \\ ${ }^{2}$ Community Medicine Specialist, Shahid Beheshti University of Medical Sciences, Tehran, Iran \\ ${ }^{3}$ Iranian Research Center on Healthy Aging, Sabzevar University of Medical Sciences, Sabzevar, Iran \\ ${ }^{4}$ Department of Internal Medicine, Rasoul-e Akram Hospital, School of Medicine, Iran University of Medical Sciences, Tehran, Iran
}

\section{AR T I C LE IN F O}

Article Type:

Original

\section{Article History:}

Received: 8 August 2016

Accepted: 28 May 2017

Published online: 2 June 2017

\section{Keywords:}

Hemodialysis

Self-transcendence

Peer support group

\begin{abstract}
A B S T R A C T
Introduction: End-stage renal disease (ESRD) has been the significant reason of death and disability around the world and it is at increased risk all over the world.

Objectives: This study was conducted to determine the relationship between selftranscendence and physically-healthy patients undergoing hemodialysis who participate in peers support group.

Patients and Methods: This was a randomized clinical trial with control and intervention groups of 64 each, which was conducted among patients admitted to Sabzevar hospital for hemodialysis in the year 2013. Randomized sampling was used and 2-hour peer support sessions were held for 8 weeks for the intervention group. The health problems related patients' needs and interests were discussed in such sessions. The research tools were questionnaires, demographic data, Reed's self- transcendence scale, and physical function section of quality of life questionnaire for patients on dialysis (KDQOL-SFTM). To analyze the data, descriptive and inferential statistics were employed using SPSS software (version 18).

Results: A significant difference was observed between intervention and control groups in terms of self-transcendence scores and physical health status $(P<0.05)$. Also, there was a significant direct relationship between the self-transcendence scores and improved physical function $(r=0.56, P<0.05)$.

Conclusion: The results showed that promoting self-transcendence leads to enhanced physical health status and the quality of life among patients receiving hemodialysis.
\end{abstract}

Implication for health policy/practice/research/medical education:

This study was aimed to determine the impact of self-transcendence on physically-healthy patients undergoing hemodialysis who participate in peer support group. This was a randomized clinical trial with control and intervention groups of 64 each. Eight weeks of peer support sessions were held in 2-hour sessions for the intervention group. The research tools were Reed's self- transcendence tool and KDQOL-SFTM. There was a significant difference between intervention and control groups in terms of self-transcendence scores and physical health status $(P<0.05)$. Also, a direct correlation was found between the selftranscendence scores and improved physical function $(r=0.56, P<0.05)$. According to the research results, improved level of self-transcendence leads to improved physical health in patients receiving hemodialysis.

Please cite this paper as: Malek Khahi A, Mohseny M, Soleimany F, Vejdani M, Keshvardoost A, Amiri P. Relationship between self-transcendence and physically-healthy patients under hemodialysis in participating in peer-support group; a randomized clinical trial. J Renal Inj Prev. 2017;6(4):253-258. DOI: 10.15171/jrip.2017.48.

\section{Introduction}

End-stage renal disease (ESRD) has been the significant reason of death and disability around the world (1). It is at increased risk all over the world. The numbers of ESRD treated patients were 2456000 people around the world in 2009. 1895000 of these patients were placed on dialysis 
(2). It is estimated that by 2020 the dialysis population will reach 3500000 , based on statistics (3). The common therapy for ESRD is hemodialysis (4). Starting therapy on hemodialysis patients at recovery will improve life and life expectancy. Despite these benefits, hemodialysis therapy may cause side effects such as dizziness, weakness, lethargy, tremors, muscle cramps, coughing, and irregular (5). Patients are exposed to high physical, psychological and social risks (6). The psychosocial risks such as changes in imaginations, behavior, etc. expose patients to daily tensions (7). Patients are often worried about their unpredictable future and suffer depression and death fear because of their chronic disease $(8,9)$. The quality of life level of dialysis treated patients is lower than that of ordinary people (10). The chronic and weakening nature of this disease, the long-lasting therapy cause actual and potential risks (11) thus revealing the need for support (6). The results indicate the effect of self-transcendence on self-care and the quality of life of chronic patients (12). The word self-transcendence is associated with spirituality and the effort to gain self-esteem (13). It is a nursing descriptive theory designed by Palma Reed in 1991, aimed to increase the health perception in those who are vulnerable or close to death (14). Self-transcendence theory was first developed with regard to mental health and welfare among the elderly, and received much attention from researchers (15). The theory has been used across the life span beyond childhood into older adulthood during past years (14). The main concepts of the theory include vulnerability, self-transcendence, wellbeing, moderating-mediating factors and point of intervention (14).

Self-transcendence is the expansion of self-boundaries and being aware of the dimensions beyond the self. It is formed as a developmental talent (or maybe a survival mechanism) from a person's experiences of health and illness (14).

As a person transcends, he feels that the boundaries around are without any physical or temporal limitations (16).

Self-transcendence is gained by helping others (17). It helps a person to organize disease challenges inside some meaningful systems to make person feel better (14) and accept death as a part of life and find spiritual meanings in life (14). In this way, nursing care can be a facilitator of patients' internal sources and a way to use others' supports to reach the self-transcendence and a higher level of health (13).

However, how does self-transcendence improve? Interpersonal approaches like phone and the Internet that focus on people's contact with others can facilitate self-transcendence. Consulting with peer group and other supportive groups is one of the approaches that a nurse can apply for the patients (14). Supportive groups are often one of the effective communicating ways for those who have difficult situations in their lives. They gather the people with the same experiences and facilitate group member's communication, sharing of experiences, transferring of information about strategies of adaptation with problems, and making of a situation to help each other in order to reach self-transcendence $(18,19)$.

The studies show that self-transcendence has a significant effect on increasing self-care in patients (20-22) sense of having a life goal (23), and quality of life among patients with incurable diseases (24).

Due to the absence of organized groups in Iran (25), individual differences in patients and their influences on the people who have experienced the same situation, and lack of research on the self-transcendence and support groups, the researchers conducted the current study and established peer groups in order to investigate the impact of support groups on the self-transcendence, physical functionality, and, ultimately, the relation between the self-transcendence and physical functionality in patients undergoing hemodialysis through sharing the problems and solutions to the patients.

\section{Objectives}

- To determine physically-healthy patients under hemodialysis participating in peer-support group;

- To determine self-transcendence patients under hemodialysis participating in peer-support group;

- To determine relationship between self-transcendence and physically-healthy patients under hemodialysis participating in peer-support group.

\section{Patients and Methods}

The study is a randomized clinical trial. The statistical population comprised all ESRD patients admitted the hospitals affiliated with the Medical Science University of Sabzavar in 2013.

\section{Sampling method}

Of 110 qualified patients (those undergone at least 6 months of hemodialysis and aged over 18), 64 patients were selected randomly regarding at the confidence interval of 95. Patients were assigned to two groups: intervention and control groups using the block permutation method. Four blocks were used and control group was named A and intervention one was named $B$. The various possible permutation scenarios were written e.g. AABB, ABBA, $\mathrm{BAAB}, \mathrm{ABAB}$, etc. Each of these blocks were written on a paper and dropped in a jar and the first block was taken from it and the process was continued until all blocks were determined.

On the first day of the trial, the objectives and methods were explained to the subjects and informed written consent was obtained from all participants.

\section{Intervention \\ The control group received routine care of dialysis while intervention group was formed to implement the intervention peer support group. The peer support group was formed for the purpose of intervention. The most appropriate group size for medical changes is 8-12 (26). Therefore, about 10-12 individuals were assigned to each group. It was thus hoped that there would remain at least}


8 individuals in each group if some decided to withdraw from the study. Ten, 10 and 12 individuals attended groups 1,2 and 3, respectively. The placement was consistent with the hemodialysis program. In order to prevent error, the intervention and control groups were arranged in separated shifts for dialysis so as not to meet each other. Group meetings were scheduled for 8 sessions in 8 weeks with each session being 2 hours long (27). Those who were absent received the topics via phone contact with the researcher or other members of the group. If they were absent in more than two sessions, the individual's information would be deleted. The group support management was the same for each group. Ideological and cultural issues were taken into consideration during the meetings. Also transportation service was provided to transport patients to the site of the meetings.

Topics discussed in each group were consistent with patient's needs and interests and health problems as questioned from groups at the first session. The seven next topics also were prioritized according to the feedbacks received. Topics to be discussed were determined based on Reed's self-transcendence scale (STS). According to Reed, the items in STS can be used to develop support groups and for education and spiritual discussions in target groups (14). Approaches such as adapting with physical changes and difficulties, adapting with present situation, building a new concept of life, and using others' experiences and opinions were emphasized.

\section{Research tools}

Tools included demographic questionnaire (Reed's STS) and, KDQOL-SFTM. The quality of life questionnaire is a specific tool for assessing quality of life among patients undergoing hemodialysis, which covers both public and private aspects in relationship to quality of life. The general aspect of quality of life includes physical and emotional conditions in seven domains. Specific aspect comprises nine domains: limitations associated with kidney disease (11 questions), mental problems associated with health problems (6 questions), healthrelated physical performance (12 questions), general state of health (3 questions), family satisfaction associated with health (4 questions), sleep condition (scoring 0-100), health-related job situation (2 questions), sexual relations (2 questions) and satisfaction with care and staffs (3 questions). The score for each aspect ranged 0-100. Higher scores indicated better quality of life (28). Reliability and validity of the questionnaire in Iranian population have been investigated by Yekaninejad et al. Additionally, Cronbach alpha for various aspects of the questionnaire was reported at $0.73-0.93$ (29). The tool developed by Reed (Reed's STS) has 15 items on Likert scale (scores of 15-60). High score indicates high selftranscendence. The Cronbach alpha coefficient was $0.72-$ 0.93. It was localized and translated into Persian (30). To determine the validity of quality of life in questionnaire for patients with renal failure, the content validity method was applied. The inventory was administrated to 10 expert professors in relevant field and based on their opinion, necessary modifications were done. In the present paper, for the determination of the reliability of two instruments, namely, self-transcendence and quality of life for dialysis patients, the test-retest method was employed. Inventory was administered to the two groups of 10 patients within a week and the correlation coefficient for renal patients' quality of life questionnaire was 0.91 while for selftranscendence questionnaire, it was 0.81 , and thus the reliability of the instrument was established.

The tools were filled in at the beginning and the end of the interventions by patients themselves. For illiterates, questionnaires were completed by attendants.

During the meeting, data of some participants were excluded. Three participants were excluded due to kidney transplant, and 4 due to the absence of more than two sessions and two because of the lack of desire to continue. Data from 28 cases in the intervention group and 27 cases in the control group were analyzed.

\section{Ethical issues}

The research followed the tenets of the Declaration of Helsinki; informed consent was obtained; and the research was approved by the ethical committee of Sabzevar University of Medical Sciences. The research has also an Iranian registry for clinical trials (Identifier: IRCT2014082018882N1, http://en.search.irct.ir).

\section{Statistical analysis}

The SPSS version 18 was used for analyzing the data. Descriptive and inferential statistics were also used. The independent $t$ test was used for self-transcendence comparison between two groups at the end of the study. The paired $t$ test was used for internal test. The analysis of covariance (ANCOVA) was used for analyzing the impact of the contextual variables. It was significant with at $0.95 \%$ $(P<0.05)$.

\section{Results}

The demographic information is presented in Table 1 . The average scores for self-transcendence and physical function of hemodialysis patients are showed in Table 2; the figures indicates a significant difference between the average scores of self-transcendence and physical health between two groups after intervention $(P<0.05)$.

Figure 1 shows the correlation between self-transcendence and physical functional status. There is a direct and significant correlation between increased levels of selftranscendence and increase in physical functional status $(P=0.001, r=0.56)$.

\section{Discussion}

The comparison of average scores of physical performance of the control and intervention groups at the end of the study showed a significant difference between two groups in terms of physical performances. In the intervention group, participation in the peer-group significantly improved physical performances of hemodialysis 
Table 1. The relative frequency separately shown in terms of demographic characteristics

\begin{tabular}{|c|c|c|c|}
\hline \multirow{2}{*}{$\begin{array}{l}\text { Demographic } \\
\text { information }\end{array}$} & \multicolumn{2}{|c|}{ Groups } & \multirow{2}{*}{$P$ value } \\
\hline & Intervention & Control & \\
\hline Age (STD) mean/year & $13.29 \pm 47.04$ & $13.20 \pm 48.04$ & 0.65 \\
\hline Sex & & & 0.80 \\
\hline Men & 25 & 22.2 & \\
\hline Women & 75 & 78.8 & \\
\hline Marital status (\%) & & & 0.42 \\
\hline Single & 82.1 & 85.2 & \\
\hline Married & 14.3 & 7.4 & \\
\hline Widow & 0 & 7.4 & \\
\hline Divorced & 3.6 & 0 & \\
\hline Education (\%) & & & 1 \\
\hline Illiterate & 7.1 & 11.1 & \\
\hline Primary school & 35.7 & 33.3 & \\
\hline Secondary school & 39.3 & 37 & \\
\hline High school & 17.9 & 14.8 & \\
\hline University & 0 & 3.7 & \\
\hline Employment status (\%) & & & 0.95 \\
\hline Worker & 25 & 14.8 & \\
\hline Employer & 7.1 & 7.4 & \\
\hline Housewife & 21.4 & 25.9 & \\
\hline Self employed & 14.3 & 14.8 & \\
\hline Unemployed & 25 & 29.6 & \\
\hline Retired & 3.6 & 7.4 & \\
\hline Student & 3.6 & 0 & \\
\hline Income (\%) & & & 0.67 \\
\hline Good & 3.6 & 7.4 & \\
\hline Average & 39.3 & 29.6 & \\
\hline Weak & 57.1 & 0.63 & \\
\hline Background dialysis (y) & $2.08 \pm 2.6$ & $1.25 \pm 2.3$ & 0.98 \\
\hline
\end{tabular}

patients. The results were consistent with Jadid-Milani and Messmer Uccelli et al who studied patients suffering MS (19,30). However, the study was inconsistent with Coward's research on American women with breast cancer in 2003. In the latter, no significant difference in physical performances of the two groups was detected after the intervention and peer-group participation. This can be due to the 'large' number of support group members in Coward's research which reduces the effectiveness of the support group (31). The increase of physical performances after the group participation revealed the necessity of establishing peer support groups. These patients feel that they belong to the group when they start to talk to each other and that they share similar problems that they all have in common. In fact, members' positive experiences and their shared experiences are obtained with no training. They also learn how to get information and show

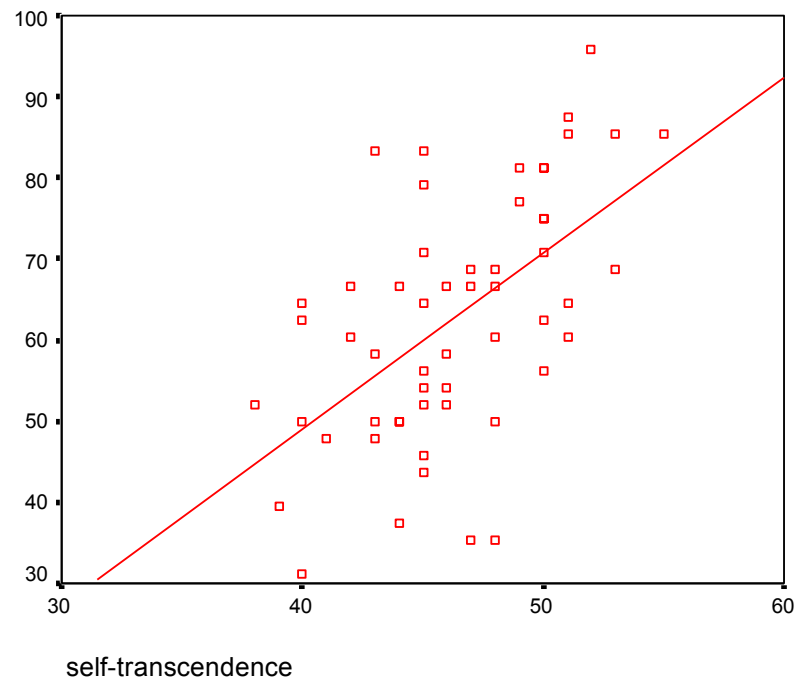

Figure 1. The correlation between self-transcendence and physical functional status of Sabzevar's hemodialysis patients after participating in peer groups for intervention and control groups in 2013.

sympathy to others (32), which information exchange and adaptation skills takes place in the group (33).

Our results showed a significant difference between selftranscendence score of both intervention and control groups at the end of the intervention. Few intervention studies have been performed regarding self-transcendence and Reed's theory. The results of the present study are consistent with Jadid Milani et al who studied patients undergoing multiple sclerosis (12). However, our results are inconsistent with Chin-A-Loy and Fernsler (34). Further, the results of our study were inconsistent with Chen et al, who examined the contribution of increased self-transcendence and positive attitude in nursing students in the university of America to the care provided to the elderly. In their study, the nursing intervention did not improve self-transcendence level of the students significantly (35). Also, Lamet et al, who studied level selftranscendence and positive attitude in providing of care to the elderly by nursing students concluded that the selftranscendence level had no meaningful changes before and after intervention (36). Differences can be related to the target group of Reed's theory, which was the nursing group in that case. Nursing students experience situations of providing care to the elderly during their education, which can be a reason for the lack of student's increased self- transcendence level. But in our study and Milani's, there were patients who showed more vulnerability.

Table 2. Average scores for the self-transcendence and physical function of Sabzevar's hemodialysis patients participating in peer groups for the intervention and control groups in 2013

\begin{tabular}{lccc}
\hline & \multicolumn{2}{c}{ Groups } & \\
\cline { 2 - 3 } Variables & Intervention & Control & Difference between intervention and control \\
\cline { 2 - 3 } & $\begin{array}{c}\text { After intervention } \\
\text { Mean } \pm \text { SD }\end{array}$ & $\begin{array}{c}\text { After intervention } \\
\text { Mean } \pm \text { SD }\end{array}$ & Mroups \\
\hline Self-transcendence & $48.64 \pm 3.09$ & $43.8 \pm 3.16$ & $\mathrm{P}=0.0001$ \\
Physical function status & $68.63 \pm 13.41$ & $56.35 \pm 14.51$ & $\mathrm{P}=0.002$ \\
\hline
\end{tabular}


Patients undergoing hemodialysis because of their chronic diseases feel more self-transcendence and better quality of life. Improved self-transcendence in our study can be due to social activities, sharing of problems and problem solving in peer-group. Peer-group sessions helped participants expand their boundaries by contemplating themselves and accepting their situation. It also helped them have responsibility and concern about others by using others experiences and be hopeful to improve their situation.

It is seen from the results that participating in peer group increased the self-transcendence score of hemodialysis patients. Patients understand and accept their situation and pay attention to other's welfare and experiences as they participate in peer-group. They share their knowledge with others as well. They also try to improve their situation by adapting others' experiences with theirs concerning future. On the other hand, sense of being accepted by the group members itself raises self-transcendence among patients (32).

In the present study, a significant direct relationship was observed between increased self-transcendence and physical performance. Other studies also indicate a relationship between self-transcendence on the one hand and health indices and physical health on the other hand. Hoshi studied hospitalized Japanese elderlies and showed a significant relationship between vulnerability, self-transcendence, and welfare as well as between self-transcendence and welfare (37). Examining selftranscendence and quality of life in $46 \mathrm{HIV}$-positive patients, Mellors et al revealed a significant correlation between patients' general condition and psycho-spiritual performance and self-transcendence (20). Ranquist and Reed scrutinizing 61 homeless cases confirmed a positive relationship between self-transcendence and physical health and welfare (38).

The results can be useful for education and management fields as well. Peer groups created by nurses for hemodialysis patients and other chronic patients can improve selftranscendence level as well as causing patients' families to better understand the disease and its condition and thus provide better environment for patients at home.

\section{Conclusion}

The nursing interventions improve self-transcendence almost without cost and clinical requirement. Selftranscendence creates new concepts for patients undergoing hemodialysis. Patients learn from peers how to cope with disease. They can deal with their concerns by gaining more knowledge about disease and how to control it. Such improved knowledge changes patient's attitudes and improves their health. Therefore, nurses can make interventions using self-transcendence hypostasis to improve patients undergoing hemodialysis.

\section{Limitations of the study}

The possibility of exchanging information in the intervention and control groups during dialysis. In order to prevent errors, the intervention and control groups were arranged in separate shifts for dialysis to ensure that they do not meet.

\section{Acknowledgments}

We are greatly indebted to Sabzevar University of Medical science for the fund and to the Vasei hospital and its members and patients for their outmost cooperation.

\section{Authors' contribution}

All authors contributed to design of the research and the data analysis. MV and AM prepared the manuscript. All authors read, revised, and approved the final manuscript.

\section{Conflicts of interest}

The author declared no competing interests.

\section{Ethical considerations}

Ethical issues (including plagiarism, data fabrication, double publication) have been completely observed by the authors.

\section{Funding/Support}

The study is based on MSc (Master's) degree thesis (\#9014288p) presented at Faculty of Nursing and Midwifery, Sabzevar University of Medical Science, Sabzevar, Iran.

\section{References}

1. Smeltzer SC, Bare BG, Hinkle JL, Cheever KH. Brunner and Suddarth's Textbook of Medical-Surgical Nursing. Philadelphia: Lippincott; 2012.

2. Fresenius Medical Care: ESRD patient: Global view of ESRD Patients. 2009. Available from: http://visionfmc.com /?action=showDetail\&id=pag1311\&lg=I.

3. Davids MR. Chronic kidney disease - the silent epidemic. CME. 2007;25:378-82.

4. Aliloo LL, Shakibi A, Shargh A. The efficacy of home care education on knowledge and performance of hem dialysisrenal patients discharged from hspitals. Urmia Med J. 2011;22:410-5. [Persian].

5. Phipps W, Sands J, Marker J. Medical-Surgical Nursing Concept: Clinical Practice. St. Louis: Mosby; 1999.

6. Tayyebi A, Salimi S, Mahmoudi H, Tadrisi SD. Comparison of quality of life in haemodialysis and renal transplantation pateints. Iran J Crit Care Nurs. 2010;3:7-8.

7. Rafiee F, Rambod M, Hoseyni AF. Quality of life in end stage renal disease and its related factors. Iran J Nurs. 2011;23:35-42.

8. Kirby K. Nursing textbooks: comparative representation of physicians and advanced practice nurses [Thesis]. US: Hampshire University; 2013.

9. Eslami AA, Rabiei L, Khayri F, Rashidi Nooshabadi MR, Masoudi R. Sleep quality and spiritual well-being in hemodialysis patients. Iran Red Crescent Med J. 2014;16:e17155. doi: 10.5812/ircmj.17155.

10. Lindqvist R, Sjoden PO. Coping strategies and quality of life among patients on continuous ambulatory peritoneal dialysis (CAPD). J Adv Nurs. 1998;27:312-9. doi: 10.1046/j.1365-2648.1998.00523.x. 
11. Rahimi A, Ahmadi F, Gholyaf M. Effects of applying continuous care model on quality of life in hemodialysis patients. Razi J Med Sci. 2006;13:123-34.

12. Jadid-Milani M, Ashktorab T, Abed-Saeedi Z, Alavi-Majd $\mathrm{H}$. The impact of self-transcendence on physical health status promotion in multiple sclerosis patients attending peer support groups. Int J Nurs Pract. 2015;21:725-32. doi: 10.1111/ijn.12186

13. Reed PG. Demystifying self-transcendence for mental health nursing practice and research. Arch Psychiatr Nurs. 2009;23:397-400. doi: 10.1016/j.apnu.2009.06.006.

14. Reed PG. Theory of Self-transcendence. New York: Springer Publishing Company; 2008.

15. Kausch KD, Amer K. Self-transcendence and depression among AIDS memorial quilt panel makers. J Psychosoc Nurs Ment Health Serv. 2007;45:44-53.

16. Coward DD, Kahn DL. Transcending breast cancer: making meaning from diagnosis and treatment. J Holist Nurs. 2005;23:264-83. doi: 10.1177/0898010105277650.

17. Jadid Milani M, Amiri P, Vejdani M, Salehiniya $H$, Malekkhahi A. The effect of peer support group on selftranscendence in patients undergoing haemodialysis. Biomed Res Ther. 2017;4:1198-209. doi: 10.15419/bmrat. v4i03.157.

18. Nichols KA, Jenkinson JD. Leading a support group : A practical guide. England: McGrawHill; 2006.

19. Messmer Uccelli M, Mancuso Mohr L, Battaglia MA, Zagami P, Mohr DC. Peer support groups in multiple sclerosis: current effectiveness and future directions. Mult Scler. 2004;10:80-4. doi: 10.1191/1352458504ms973oa

20. Mellors MP, Riley TA, Erlen JA. HIV, self-transcendence, and quality of life. J Assoc Nurses AIDS Care. 1997;8:59-69. doi: 10.1016/S1055-3290(97)80018-0.

21. Upchurch S. Self-transcendence and activities of daily living. The woman with the pink slippers. J Holist Nurs. 1999;17:251-66. doi: 10.1177/089801019901700303

22. Upchurch S, Mueller WH. Spiritual influences on ability to engage in self-care activities among older African Americans. Int J Aging Hum Dev. 2005;6:77-94. doi: 10.2190/X05G-XGRL-778R-UHBW.

23. Nygren B, Alex L, Jonsen E, Gustafson Y, Norberg A, Lundman B. Resilience, sense of coherence, purpose in life and self-transcendence in relation to perceived physical and mental health among the oldest old. Aging Ment Health. 2005;9:354-362. doi: 10.1080/1360500114415

24. Neill J. Transcendence and transformation in the life patterns of women living with rheumatoid arthritis. ANS Adv Nurs Sci. 2002;24:27-47.

25. Sharif F, Abshorshori N, Hazrati M, Tahmasebi S, Zare N, Masoumi S. The effect of peer-led education on the life quality of mastectomy patients referred to breast cancerclinics in Shiraz, Iran 2009. Health Qual Life Outcomes. 2010;8:1-7. doi:10.1186/1477-7525-8-74.

26. Mead S, MacNeil C. Peer support: what makes it unique? International Journal of Psychosocial Rehabilitation. 2006;10:29-37.

27. Mohr DC, Burke H, BecknerV, Merluzzi N. A preliminary report on a skills-based telephone-administered peer support programme for patients with multiple sclerosis. Mult Scler. 2005;11:222-6. doi: 10.1191/1352458505ms1150oa.

28. Hays RD, Kallich JD, Mapes DL, Coons SJ, Carter WB. Development of the Kidney Disease Quality of Life (KDQOLTM) Instrument. Qual Life Res. 1994;3:329-38. doi: $\quad 10.1007 / B F 00451725$.

29. Yekaninejad MS, MohammadiZeidi I, Akaberi A, Golshan A, Pakpour A. Validity and reliability of the Kidney Disease Quality of Life - Short Form (KDQOL-SF ${ }^{\mathrm{TM}} 1.3$ ) in Iranian patients. J North Khorasan Univ Med Sci. 2012;4:216-72.

30. Jadid-Milani M. Testing Reed's Self-Transcendence Theory: Promotion of Physical Health Status in Multiple Sclerosis (MS) Peer Support Groups [PhD thesis]. Tehran: Shahid Beheshti University; 2012.

31. Coward DD. Facilitation of self-transcendence in a breast cancer support group: II. Oncol Nurs Forum. 2003;30:291300. doi: 10.1188/03.ONF.291-300

32. Nguyen TA, Oosterhoff P, Ngoc YP, Wright P, Hardon A. Self-help groups can improve utilization of postnatal care by HIV-infected mothers. J Assoc Nurses AIDS Care. 2009;20:141-52. doi: 10.1016/j.jana.2008.10.006.

33. Johns G, Saks AM. Organizational Behavior: Understanding and Managing Life at work. Toronto: Pearson Canada; 2005.

34. Chin-A-Loy SS, Fernsler JI. Self-transcendence in older men attending a prostate cancer support group. Cancer Nurs. 1998;21:358-63. doi: 10.1097/00002820-19981000000007

35. Chen S, Walsh SM. Effect of a creative-bonding intervention on Taiwanese nursing students' self-transcendence and attitudes toward elders. Res Nurs Health. 2009;32:204-16. doi: 10.1002/nur.20310.

36. Lamet AR, Sonshine R, Walsh SM, Molnar D, Rafalko S. A pilot study of a creative bonding intervention to promote nursing students' attitudes towards taking care ofolder people. Nurs Res Pract. 2011;2011:537634. doi: $10.1155 / 2011 / 537634$.

37. Hoshi M. Self-transcendence, vulnerability and well-being in hospitalized Japanese elders [dissertation]. Tucson, AZ: The University of Arizona, College of Nursing; 2008.

38. Runquist JJ, Reed PG. Self-transcendence and well-being in homeless adults. J Holist Nurs. 2007;25:5-13. doi: $10.1177 / 0898010106289856$

Copyright (C) 2017 The Author(s); Published by Nickan Research Institute. This is an open-access article distributed under the terms of the Creative Commons Attribution License (http://creativecommons.org/licenses/by/4.0), which permits unrestricted use, distribution, and reproduction in any medium, provided the original work is properly cited. 